\title{
DESTINAÇÃO IRREGULAR DE RESÍDUOS DE CONSTRUÇÃO E DEMOLIÇÃO (RCD) E SEUS IMPACTOS NA SAÚDE COLETIVA
}

\author{
João Alexandre Paschoalin Filho \\ Doutor em Engenharia Agrícola pela Universidade Estadual de Campinas - UNICAMP \\ Professor da Universidade Nove de Julho - UNINOVE \\ jalexandre@uninove.br \\ Gustavo Silveira Graudenz \\ Doutor em Patologia pela Universidade de São Paulo - USP \\ Professor da Universidade Nove de Julho - UNINOVE \\ graudenz@uninove.br
}

\section{RESUMO}

Resíduos de construção e demolição representam grande parte do volume final de resíduos sólidos urbanos (RSU). Com o crescimento da participação da construção civil no Produto Interno Bruto brasileiro, a geração de resíduos provenientes deste setor passou a consistir em um importante problema ambiental. Formas de reaproveitamento destes resíduos, muitas vezes na composição de novos materiais, e o desenvolvimento de modelos e ferramentas de gestão têm sido uma constante no debate junto ao meio técnico, no intuito de se mitigar os efeitos causados pelo impacto da construção civil no meio ambiente. Contudo, a ausência de políticas públicas objetivas que considerem como problema real a geração, o manuseio e a deposição destes resíduos ainda se constitui como importante empecilho na adoção de práticas de sustentabilidade. Essa pesquisa exploratória relata a situação da deposição irregular de resíduos de construção e demolição (RCD) em três municípios brasileiros. Os dados necessários a este estudo foram obtidos por meio de pesquisa documental. O objetivo desta pesquisa é analisar o problema de geração e destinação final de resíduos sólidos de construção civil e seus impactos na saúde coletiva por meio de um estudo comparativo em três municípios brasileiros: São Paulo/SP, Uberlândia/MG e Recife/PE. Dessa forma, pretende-se, com esse estudo, contribuir com o meio técnico na discussão a respeito da importância da correta destinação dos resíduos de construção e demolição e seus impactos, causados pela sua destinação inadequada.

Palavras-chave: Construção civil; Resíduos; Saúde coletiva; Sustentabilidade.

\section{ALLOCATION OF ILLEGAL CONSTRUCTION AND DEMOLITION WASTE (RCD) AND ITS IMPACT ON HEALTH COLLECTIVE}

\begin{abstract}
With the increasing participation of construction in Brazilian PIB, the production of waste from this sector consists to be an important problem needing to be solved. Forms of reuse of waste, often in the composition of new materials, and the development of models and management tools have been in a constant debate by technical means in order to mitigate the effects caused by the impact of construction on the environment, both natural and urban. The absence of an objective public policy that considers this situation as a real problem is still an important obstacle in the adoption of sustainable practices. This study reports the deposition of irregular construction and demolition wastes in three Brazilian cities and discusses the impacts of this illegal action in public health. The information for this study was obtained by consulting the available literature. This work aims to contribute to the technical discussion of the importance of proper disposal of construction waste and demolition and its impact both in the urban environment and its effects on public health caused by improper disposal.
\end{abstract}

Key-words: Waste; Civil construction; Sustainability; Collective health.

* Apoio recebido do Fundo de Apoio a Pesquisa - FAP/UNINOVE 


\section{INTRODUÇÃO}

Nos centros urbanos, responsáveis por agregar a maior parte da população, são muitos os sinais de impactos ao meio ambiente provocados pelo homem. O ritmo imposto pelo crescimento econômico aos diversos setores da cadeia produtiva e o consumo cada vez mais barato e intenso, têm causado a geração de vultosas quantias de Resíduos Sólidos Urbanos (RSU). As ausências de políticas públicas efetivas e de metodologias consistentes de gerenciamento e manejo destes resíduos, muitas vezes, propiciam alternativas de solução insuficientes ou não adequadas, o que acaba agravando ainda mais esta problemática.

De uma forma geral, entre os resíduos que compõem a enorme massa de RSU gerada diariamente, verifica-se que grande percentual deve-se àqueles provenientes de atividades ligadas à construção civil. O crescimento deste setor, alavancado pelo atual panorama econômico e a necessidade de se atender ao déficit habitacional, tem causado significativo impacto ambiental, quer seja pela crescente demanda por matéria-prima, ou pela geração de resíduos.

Dados nacionais apontam que a quantidade de entulho da construção civil é superior, em massa, ao lixo doméstico. Bidone (2001) apud Morais (2006) cita a relação de uma tonelada de lixo urbano recolhido para cada duas toneladas de resíduo de construção e demolição (RCD). Morais (2006) apresenta dados relativos a algumas cidades brasileiras de médio e grande porte, nas quais a massa de RCD, em percentual, varia entre $41 \%$ a $70 \%$ da massa total de resíduos sólidos urbanos (RSU).

Tal situação retrata um aspecto paradoxal, pois ao se promover, por meio de obras civis, a melhoria das condições urbanísticas de um local, também se promove o aumento da demanda por matérias-primas naturais, e por consequência, a geração de resíduos e impactos ao meio ambiente.

No Brasil, a preocupação acerca dos resíduos em geral ainda é recente. Ao se considerar Resíduos de Construção e Demolição (RCDs) pode-se citar a Resolução no 307 do Conselho Nacional do Meio Ambiente - Conama (2002), primeiro instrumento legal que fixou prazos para as administrações municipais elaborarem e implantarem planos de gestão para os RCDs.

O objetivo desta pesquisa é analisar o problema de geração e destinação final de resíduos sólidos de construção civil e seus impactos na saúde coletiva por meio de um estudo comparativo em três municípios brasileiros: São Paulo/SP, Uberlândia/MG e Recife/PE. Dessa forma, pretendese com esta pesquisa contribuir com o meio técnico na discussão a respeito da importância da correta destinação dos resíduos de construção e demolição e seus impactos, causados pela sua destinação inadequada.

\section{FUNDAMENTAÇÃO TÉORICA}

A seguir, é apresentada a fundamentação teórica necessária para a compreensão do objeto de estudo deste trabalho.

\subsection{A indústria da construção civil e a produção de RCD}

A construção civil possui relevante importância no desenvolvimento do país. Estima-se que este setor seja responsável pela geração de investimentos superiores a $\mathrm{R} \$ 90$ bilhões por ano. A demanda por mão de obra também acompanha a necessidade de crescimento desta atividade, que é responsável pela geração de 62 empregos indiretos para cada 100 empregos diretos. Este setor econômico também desempenha importante papel social, uma vez que contribui diretamente na redução do déficit habitacional e de infraestrutura, indispensável ao progresso.

Contudo, a indústria da construção civil é também responsável por um consumo considerável de recursos naturais, uma vez que muitos dos insumos que entram na produção dos materiais de construção são obtidos pela extração em jazidas para atender à demanda de mercado. Estima-se que $50 \%$ dos recursos materiais extraídos da natureza estão relacionados à atividade de construção (Dias, 2004).

Revista de Gestão Social e Ambiental - RGSA, São Paulo, v. 6, n. 1, p. 127-142, jan./abril 2012. 
Além dos impactos causados pelo extrativismo, a construção civil também arca com o ônus de impor ao ambiente outras formas de agressão, tais como poluição do ar e sonora, contaminação de solo, geração de resíduos etc.

A indústria de materiais de construção é igualmente responsável por outra gama de impactos negativos. $\mathrm{O}$ ramo cimenteiro no Brasil contribui com a geração de mais de $6 \%$ do $\mathrm{CO}_{2}$ gerado no país. (John, 2000 apud Shneideir, 2003)

A tabela seguinte, apresentada por Pinto (1999), traz a concentração, em termos percentuais, de RCD na massa total de RSU em diversos municípios brasileiros e em alguns países.

Tabela 1: Porcentagem de RCD na massa total de RSU de diversas localidades.

\begin{tabular}{|l|c|}
\hline \multicolumn{1}{|c|}{ Localidade } & $\%$ \\
\hline Santo André/SP & 54 \\
\hline São José do Rio Preto/SP & 58 \\
\hline São José dos Campos/SP & 67 \\
\hline Ribeirão Preto/SP & 70 \\
\hline Jundiaí/SP & 62 \\
\hline Vitória da Conquista/BA & 61 \\
\hline Belo Horizonte/MG & 54 \\
\hline Campinas/SP & 64 \\
\hline Salvador/BA & 41 \\
\hline Europa Oriental & Aprox.66 \\
\hline Suíça & Aprox.45 \\
\hline Alemanha & $>60$ \\
\hline Bélgica & $>66$ \\
\hline Estados Unidos & 39 \\
\hline
\end{tabular}

Fonte: Pinto (1999).

A tabela 2, apresentada em Carneiro (2005), traz para alguns municípios a composição, em termos percentuais do RCD.

Tabela 2: Composição do RCD para alguns municípios brasileiros.

\begin{tabular}{|l|c|c|c|c|}
\hline \multirow{2}{*}{ Material } & \multicolumn{4}{|c|}{ Localidade } \\
\cline { 2 - 5 } & São Paulo/SP & $\begin{array}{l}\text { Ribeirão } \\
\text { Preto/SP }\end{array}$ & Salvador/BA & Florianópolis/SC \\
\hline $\begin{array}{l}\text { Concreto e } \\
\text { argamassa }\end{array}$ & 33 & 59 & 56 & 37 \\
\hline Solo e areia & 32 & --- & 22 & 15 \\
\hline Cerâmica & 30 & 23 & 14 & 12 \\
\hline Rochas & --- & 18 & 5 & --- \\
\hline Outros & 5 & --- & 6 & 36 \\
\hline
\end{tabular}

Fonte: Carneiro (2005).

Em todas as cidades apresentadas na Tabela 2, verifica-se que os materiais cimentícios (concreto e argamassa) foram os que apresentaram maior participação na composição da massa de RCD. Entre os municípios estudados, percebe-se que os municípios de Ribeirão Preto/SP e 
Salvador/BA possuem 59 e 56\%, respectivamente, de concentração destes materiais na massa total de RCD gerada.

John \& Agopyan (2000), comentam que a quantidade de RCD gerada por habitante, baseado em estimativas internacionais, varia entre 130 e 3000 kg/hab.ano. Para o Brasil, as estimativas de Pinto (1999) apud John \& Agopyan (2000) para cidades de Jundiaí, Santo André, São José dos Campos, Belo Horizonte, Ribeirão Preto, Campinas, Salvador e Vitória da Conquista, variam entre $230 \mathrm{~kg} / \mathrm{hab}$.ano para esta última até $760 \mathrm{~kg} / \mathrm{hab}$.ano para a primeira. Nesta amostra a mediana foi $510 \mathrm{~kg} / \mathrm{hab}$.ano, valor coerente com as estimativas estrangeiras. Já a estimativa da Prefeitura Municipal de São Paulo a partir dos dados de Brito (1999) apud John \& Agopyan (2000) é de, aproximadamente, $280 \mathrm{~kg} / \mathrm{hab}$.ano. A Tabela 3 apresenta estimativas de geração de resíduos de construção civil obtida para diversas localidades.

Tabela 3: Estimativa de geração de resíduos de construção civil.

\begin{tabular}{|c|c|c|c|}
\hline \multirow[t]{2}{*}{ País } & \multicolumn{2}{|c|}{ Quantidade anual } & \multirow[t]{2}{*}{ Fonte } \\
\hline & Mton/ano & Kg/hab & \\
\hline Suécia & 1,2 a 6,0 & 136 a 680 & $\begin{array}{l}\text { Tolstoy, Borklund \& Carlson (1998); EU } \\
\text { (1999) }\end{array}$ \\
\hline Holanda & 12,8 a 20,2 & 820 a 1300 & $\begin{array}{c}\text { Lauritzen (1998); Brossink, Brouwers \& } \\
\text { Van Kessel (1996) }\end{array}$ \\
\hline EUA & 136 a 171 & 463 a 584 & $\begin{array}{l}\text { EPA (1998); Peng, Grosskopf, Kilbert } \\
\text { (1994) }\end{array}$ \\
\hline UK & 50 a 70 & 880 a 1120 & Detr (1998); Lauritzen (1998) \\
\hline Bélgica & 7,5 a 34,7 & 7,5 a 3359 & \multirow{4}{*}{ Lauritzen (1998), EU (1999) } \\
\hline Dinamarca & 2,3 a 10,7 & 440 a 2010 & \\
\hline Itália & 35 a 40 & 600 a 690 & \\
\hline Alemanha & 79 a 300 & 963 a 3658 & \\
\hline Japão & 99 & 785 & Kassai (1998) \\
\hline Portugal & 3,2 & 325 & EU (1999) \\
\hline Brasil & $\begin{array}{c}--- \\
\end{array}$ & 230 a 660 & Pinto (1999) \\
\hline
\end{tabular}

Fonte: John (2000).

\subsection{Classificação dos resíduos de construção e demolição (RCD)}

De acordo com a Resolução n ${ }^{\circ} 307$ do Conselho Nacional do Meio Ambiente (Conama), de 5 de julho de 2002, os RCDs recebem a seguinte denominação:

Resíduos da construção civil: são os provenientes de construções, reformas, reparo de demolições de obras de construção civil, e os resultantes da preparação e da escavação de terrenos, tais como: tijolos, blocos cerâmicos, concreto em geral, solos, rochas, metais,resinas, colas, tintas, madeiras e compensados, forros, argamassa, gesso, telhas, pavimento asfáltico, vidros, plásticos, tubulações, fiação elétrica etc., comumente chamados de entulhos de obras, caliça ou metralha.

A Resolução n॰ 307 do Conama também apresenta a definição dos seguintes itens:

a) Geradores: "São pessoas, físicas ou jurídicas, públicas ou privadas, responsáveis por atividades ou empreendimentos que gerem os resíduos (conforme definição da resolução $\mathrm{n}^{0} 307 / 2002$ )".

b) Transportadores: "São as pessoas, físicas ou jurídicas, encarregadas da coleta e do transporte dos resíduos entre as fontes geradoras e as áreas de destinação". 
c) Agregado reciclado: "É o material granular proveniente do beneficiamento de resíduos de construção que apresentem características técnicas para a aplicação em obras de edificação, de infra-estrutura, em aterros sanitários ou outras obras de engenharia".

d) Gerenciamento de resíduos: "É o sistema de gestão que visa reduzir, reutilizar ou reciclar resíduos, incluindo planejamento, responsabilidades, práticas, procedimentos e recursos para desenvolver e implementar as ações necessárias ao cumprimento das etapas previstas em programas e planos".

e) Reutilização: "É o processo de reaplicação de um resíduo, sem transformação do mesmo";

f) Reciclagem: "E o processo de reaproveitamento de um resíduo, após ter sido submetido à transformação".

g) Beneficiamento: "É o ato de submeter um resíduo à operações e/ou processos que tenham por objetivo dotá-los de condições que permitam que sejam utilizados como matéria-prima ou produto".

h) Aterro de resíduos da construção civil: "É a área onde serão empregadas técnicas de disposição de resíduos da construção civil Classe "A" no solo, visando a reservação de materiais segregados de forma a possibilitar seu uso futuro e/ou futura utilização da área, utilizando princípios de engenharia para confiná-los ao menor volume possível, sem causar danos à saúde pública e ao meio ambiente".

i) Áreas de destinação de resíduos: "São áreas destinadas ao beneficiamento ou à disposição final de resíduos".

Ainda, segundo esta resolução, os Resíduos de Construção e Demolição (RCDs) podem ser classificados em quatro grupos. Em 2004, em complementação, foi elaborada a resolução $\mathrm{n}^{\mathrm{o}} 348$, na qual é incluído o amianto como pertencente a classe de resíduos perigosos. A tabela seguinte apresenta a classificação dos RCDs de acordo com o Conama.

Tabela 4: Classificação do RCD de acordo com Conama (2002).

\begin{tabular}{|c|c|c|}
\hline Classe & Origem & Tipo de resíduo \\
\hline Classe A & $\begin{array}{l}\text { São os resíduos reutilizáveis ou } \\
\text { recicláveis como agregados }\end{array}$ & $\begin{array}{l}\text { De pavimentação e de outras obras de } \\
\text { infraestrutura, inclusive solos } \\
\text { provenientes de operações de } \\
\text { terraplenagem }\end{array}$ \\
\hline Classe B & $\begin{array}{l}\text { Resíduos recicláveis como outras } \\
\text { destinações }\end{array}$ & $\begin{array}{l}\text { Plásticos, papel, papelão, metais, vidros, } \\
\text { madeiras e outros }\end{array}$ \\
\hline Classe C & $\begin{array}{l}\text { Resíduos para os quais ainda não } \\
\text { foram desenvolvidas tecnologias ou } \\
\text { aplicações que permitam sua } \\
\text { reciclagem ou recuperação }\end{array}$ & Gesso e produtos oriundos deste \\
\hline \multirow[b]{2}{*}{ Classe D } & $\begin{array}{l}\text { Resíduos perigosos oriundos de } \\
\text { processo de construção }\end{array}$ & Tintas, solventes, óleos, amianto \\
\hline & $\begin{array}{l}\text { Aqueles contaminados, oriundos de } \\
\text { demolições, reforma e reparo, } \\
\text { enquadrados como classe I na }\end{array}$ & $\begin{array}{l}\text { Clínicas radiológicas, instalações } \\
\text { industriais e outros }\end{array}$ \\
\hline
\end{tabular}

Revista de Gestão Social e Ambiental - RGSA, São Paulo, v. 6, n. 1, p. 127-142, jan./abril 2012. 


\begin{tabular}{|l|l|l|}
\hline & NBR10.004/2004 da ABNT & \\
\hline
\end{tabular}

Fonte: Conama(2002).

Segundo Morais (2006), de acordo com NBR 10004 (ABNT, 2004) - "Resíduos Sólidos Classificação", os RCDs são ambientalmente classificados como inertes (Classe IIB), uma vez que quando submetidos a testes de solubilização estes não apresentam nenhum de seus constituintes solubilizados a concentrações superiores aos padrões de potabilidade da água.

Contudo, Morais (2006) atenta que os resíduos de "Classe C" e "Classe D", segundo a classificação do Conama, podem apresentar níveis de contaminantes que os inserem na classe de não-inertes, como é o caso do gesso, considerado pela NBR 10004 (ABNT, 2004) como um resíduo não-inerte (Classe II-A). Ou ainda, os resíduos de amianto, tintas, solventes e óleos, que podem ser considerados resíduos perigosos (Classe I), após classificação.

\subsection{Destinação dos resíduos de construção civil}

De acordo com o artigo $10^{\circ}$ da resolução n 307 do Conama, os resíduos de construção civil deverão ser destinados das maneiras apresentadas na tabela 5 a seguir.

Tabela 5: Destinação do RCD de acordo com Conama (2002).

\begin{tabular}{|c|c|c|}
\hline Classe & Origem & Destinação \\
\hline Classe A & $\begin{array}{l}\text { São os resíduos reutilizáveis } \\
\text { ou recicláveis como } \\
\text { agregados }\end{array}$ & $\begin{array}{l}\text { Deverão ser reutilizados ou reciclados na forma de } \\
\text { agregados, ou encaminhados para áreas de aterro de } \\
\text { resíduos da construção civil, sendo dispostos de } \\
\text { modo a permitir sua utilização ou reciclagem futura. }\end{array}$ \\
\hline Classe B & $\begin{array}{l}\text { Resíduos recicláveis como } \\
\text { outras destinações }\end{array}$ & $\begin{array}{l}\text { Deverão ser reutilizados, reciclados ou } \\
\text { encaminhados para áreas de armazenamento } \\
\text { temporário, sendo dispostos de modo a permitir sua } \\
\text { utilização ou reciclagem futura }\end{array}$ \\
\hline Classe C & $\begin{array}{l}\text { Resíduos para os quais ainda } \\
\text { não foram desenvolvidas } \\
\text { tecnologias ou aplicações que } \\
\text { permitam a sua reciclagem ou } \\
\text { recuperação }\end{array}$ & $\begin{array}{l}\text { Deverão ser armazenados, transportados e } \\
\text { destinados em conformidade com as normas } \\
\text { técnicas específicas. }\end{array}$ \\
\hline \multirow[b]{2}{*}{ Classe D } & $\begin{array}{l}\text { Resíduos perigosos oriundos } \\
\text { de processo de construção }\end{array}$ & \multirow[b]{2}{*}{$\begin{array}{l}\text { Deverão ser armazenados, transportados, } \\
\text { reutilizados e destinados em conformidade com as } \\
\text { normas técnicas específicas. }\end{array}$} \\
\hline & $\begin{array}{l}\text { Aqueles contaminados, } \\
\text { oriundos de demolições, } \\
\text { reforma e reparo, } \\
\text { enquadrados como classe I na } \\
\text { NBR10.004/2004 da ABNT }\end{array}$ & \\
\hline
\end{tabular}

Fonte: Conama (2002).

De acordo com o artigo $5^{\circ}$, é função de Municípios e do Distrito Federal a elaboração de um Plano Integrado de Gerenciamento de Resíduos da Construção Civil. Neste plano, deverão ser incorporados os seguintes itens: a) Programa Municipal de Gerenciamento de Resíduos da Construção Civil; b) Projetos de Gerenciamento de Resíduos da Construção Civil. O artigo $6^{\circ}$ informa que o Plano Integrado de Gerenciamento de Resíduos da Construção Civil deverá ser composto por:

I - as diretrizes técnicas e procedimentos para o Programa Municipal de Gerenciamento de Resíduos da Construção Civil e para os Projetos de Gerenciamento de Resíduos da Construção Civil a serem elaborados pelos 
grandes geradores, possibilitando o exercício das responsabilidades de todos os geradores.

II - o cadastramento de áreas, públicas ou privadas, aptas para recebimento, triagem e armazenamento temporário de pequenos volumes, em conformidade com o porte da área urbana municipal, possibilitando a destinação posterior dos resíduos oriundos de pequenos geradores às áreas de beneficiamento;

III - o estabelecimento de processos de licenciamento para as áreas de beneficiamento e de disposição final de resíduos;

IV - a proibição da disposição dos resíduos de construção em áreas não licenciadas;

V - o incentivo à reinserção dos resíduos reutilizáveis ou reciclados no ciclo produtivo;

VI - a definição de critérios para o cadastramento de transportadores;

VII - as ações de orientação, de fiscalização e de controle dos agentes envolvidos;

VIII - as ações educativas visando reduzir a geração de resíduos e possibilitar a sua segregação.

De acordo com os itens II à IV, fica sob a responsabilidade do município a disponibilização de áreas adequadas para destinação dos RCDs, além de ações de fiscalização quanto à deposição inadequada destes resíduos.

Entretanto, grandes volumes de entulho são depositados diariamente em locais não adequados em diversos municípios brasileiros, configurando-se esta situação em cena comum na rotina dos cidadãos. Ressalta-se que a prática de deposição destes resíduos em tais áreas, além de imprópria é ilegal. A figura 1 apresenta a quantidade de deposições irregulares de RCD em alguns municípios.

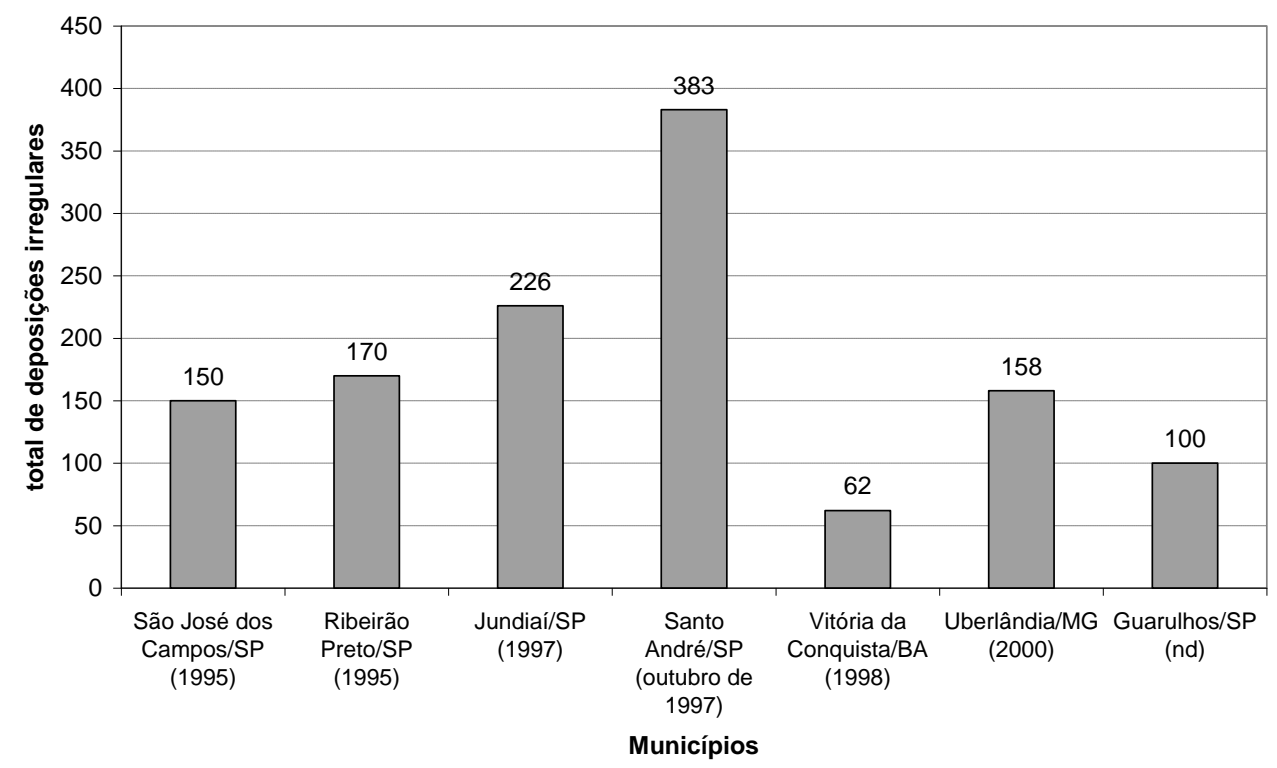

Figura 1: Deposições irregulares em alguns municípios brasileiros.

Fonte: CEF (2005). 


\section{A DEPOSIÇÃO IRREGULAR DE RCD E OS PREJUÍZOS À SAÚDE COLETIVA}

A quantidade de resíduos domiciliares cujo destino final acontece em lixões ou aterros controlados ainda é significativa. Mais preocupante ainda é a quase total falta de conhecimento sobre a destinação dos resíduos industriais, simbolizada pelas ocorrências rotineiras de depósitos clandestinos de resíduos perigosos, de acordo com Shneideir (2003)

Os principais impactos sanitários e ambientais relacionados aos RCDs talvez sejam aqueles associados às deposições irregulares, o que compromete no ambiente urbano a paisagem, o tráfego de pedestres e veículos e a drenagem pluvial. Deve-se ressaltar que esta prática, além de ilegal, resulta também na atração de resíduos não-inertes, multiplicação de vetores de doenças e outros efeitos na saúde pública.

Os RCDs dispostos inadequadamente poluem o solo, degradam paisagens e constituem em grave ameaça à saúde coletiva. $\mathrm{O}$ acúmulo destes resíduos torna-se nicho ecológico de diversas espécies de agentes patogênicos, tais como roedores, baratas, moscas, vermes, pernilongos, fungos, vírus, animais, entre outros. Estes vetores podem ser responsáveis pela transmissão de doenças respiratórias, epidérmicas, viroses, intestinais etc. A Tabela 6 apresenta vetores relacionados à disposição inadequada de resíduos sólidos urbanos e doenças transmitidas, segundo Shneideir (2003).

Tabela 6: Vetores biológicos e doenças causadas.

\begin{tabular}{|c|c|}
\hline Vetores & Doenças \\
\hline Mosca & Febre tifoide, salmoneloses, disenterias \\
\hline Mosquito & Malária,febre amarela, dengue \\
\hline Barata & Febre tifoide, cólera, amebíase \\
\hline Ratos & Leptospirose, diarreias, disenterias \\
\hline Suínos & Cisticercose \\
\hline
\end{tabular}

Fonte: Shneideir (2003).

Verifica-se também a ocorrência de sobrevida de organismos patogênicos no lixo, conforme apresentado por Rocha (1997) apud Shneideir (2003).

Tabela 7: Organismos patogênicos e sobrevida no lixo.

\begin{tabular}{|c|c|c|c|}
\hline Organismo & Doença ou condição & Comentários & $\begin{array}{c}\text { Tempo de vida no lixo } \\
\text { (dias) }\end{array}$ \\
\hline Pólio vírus & Poliomelite & $\begin{array}{c}\text { Encontrado em efluentes, } \\
\text { mas não comprovada a } \\
\text { transmissão pela água }\end{array}$ & $20-170$ \\
\hline Salmonella typhi & Febre tifoide & $\begin{array}{c}\text { Comum em esgoto e } \\
\text { efluentes após tratamento } \\
\text { em epidemias }\end{array}$ & $29-70$ \\
\hline $\begin{array}{c}\text { Mycobacterium } \\
\text { tuberculosis }\end{array}$ & Tuberculose & $\begin{array}{c}\text { Carreada por ratos em } \\
\text { esgotos }\end{array}$ & $150-180$ \\
\hline Entamoeba hystolítica & Desinteria ou amebíase & Águas contaminadas & $8-12$ \\
\hline Taenia spp & Teníase & $\begin{array}{c}\text { Contaminação pela } \\
\text { deposição de esgoto } \\
\text { diretamente na água e } \\
\text { solo }\end{array}$ & $25-40$ \\
\hline
\end{tabular}

Fonte: Shneideir (2003).

Os resíduos provenientes de demolição e construção civil apresentam, em razão de sua constituição física e volume, dificuldades para a sua destinação final. Esses não são aceitos em 
aterros sanitários e, geralmente, são acondicionados no meio ambiente urbano sob a forma de caçambas.

Embora a responsabilidade pela destinação correta dos resíduos seja do gerador, seja ele público ou privado de acordo com a resolução Conama 307 de 2004, pequenos geradores não respeitam essa determinação, causando situações de deposição desse material em vias públicas, terrenos baldios ou a beira de córregos. Essa degradação da paisagem urbana estimula a criação de pequenos lixões a céu aberto que contribuem para a proliferação de vetores de doenças e o entupimento dos sistemas de drenagem.

Em tese de mestrado defendida na Faculdade de Saúde Pública, Araujo (2000), analisou 58 recipientes metálicos coletores de RCD estacionados em ruas de São Paulo. As principais situações de risco à saúde pública e à saúde ambiental observadas quanto ao uso das caçambas coletoras foram: abarrotamento dos resíduos no recipiente; dispersão de sedimentos e materiais para a parte externa do recipiente; presença de resíduos orgânicos na caçamba (restos de alimentos que atraíam a presença de insetos); presença de resíduos perigosos (lâmpadas fluorescentes inteiras e quebradas, bateria de veículo automotor); animais junto ao recipiente (gato, pombo, cão); extravasamento de materiais perfurantes e cortantes para a parte externa da caçamba; presença de embalagens vazias (garrafas plásticas, latas, galões, embalagens de isopor), objetos vazados (louça sanitária, pneus) e nichos impermeabilizados, que retêm líquidos no seu interior, formando poças de água da chuva, que constituem ambientes favoráveis à proliferação de mosquitos e outros vetores de doenças; presença de cacos de vidro no passeio público e água empoçada na sarjeta, em volta da caçamba; presença de pessoas manuseando os resíduos sólidos descartados; falta de sinalização e de identificação regulamentadoras no coletor; o estacionamento da caçamba em aclive, declive, curvas e ou pontos que prejudicavam a visibilidade do recipiente metálico pelo pedestre, ciclista ou motorista de veículos.

A reciclagem de RCD, medida adotada por entidades certificadoras de sustentabilidade como forma de diminuição do impacto ambiental desse tipo de resíduos, também deve garantir a saúde ocupacional dos trabalhadores, com medidas voltadas para a proteção contra ruído e de exposição a poeira decorrente dos processos. (Fernandes et al. 2010). Apesar de exposição potencial a elementos químicos orgânicos capazes de gerar desde fenômenos irritativos até exposições potencialmente causadoras de câncer, esse tipo de risco ainda é considerado especulativo segundo Takata (2003).

As figuras seguintes apresentam situações de deposição irregular de resíduos. A Figura 2 apresenta o lançamento de lixo doméstico em curso d'água, provavelmente vala de lançamento de esgoto "in natura". Na figura 3 é observado o lançamento de resíduo de construção em local irregular e próximo de moradias. Estas fotografias foram colhidas na comunidade Capelinha, localizada no bairro Jardim Ipê, situado no município de São Paulo. Ressalta-se que as situações apresentadas consistem em potencial risco à saúde coletiva dos habitantes deste local. 


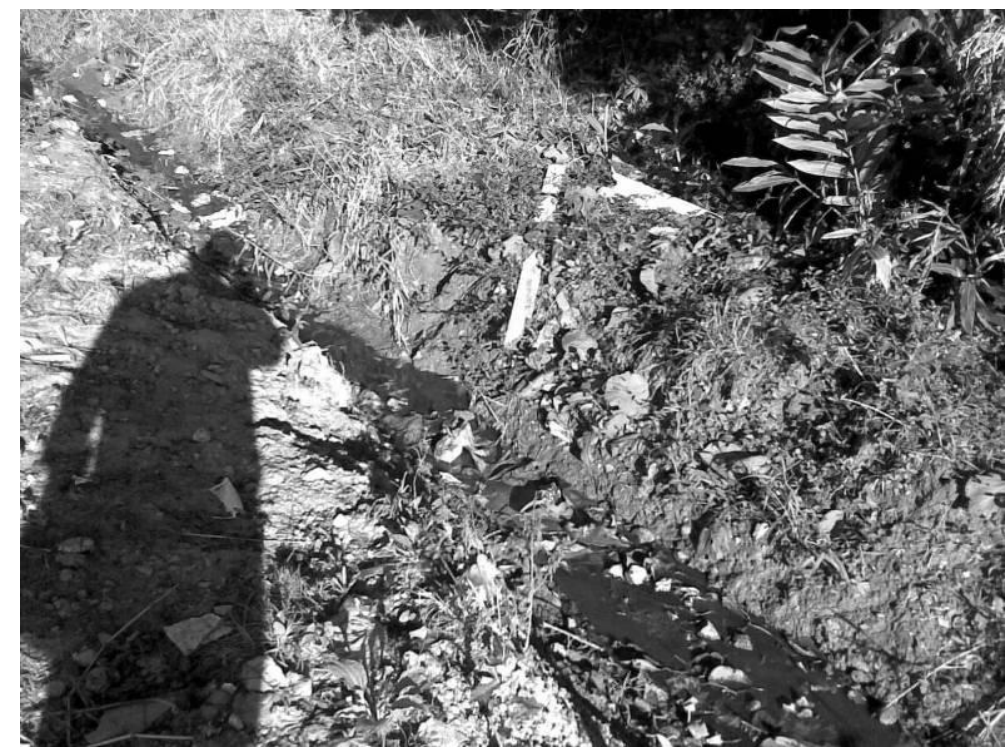

Figura 2: Lançamento de lixo doméstico em córrego.

Fonte: os autores.

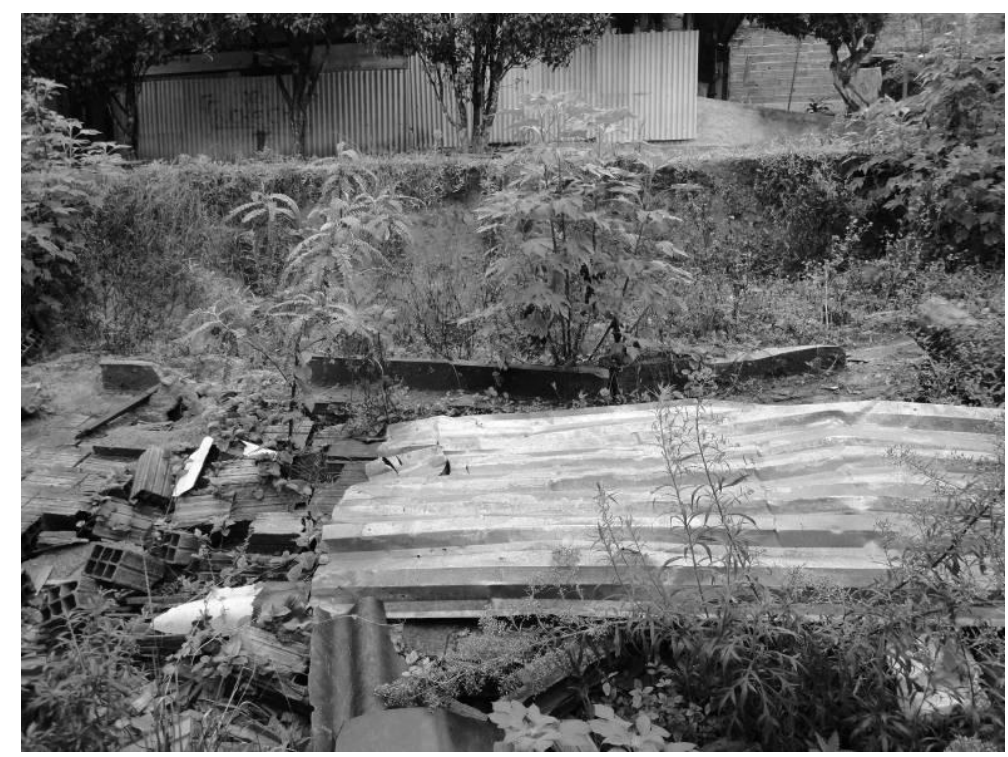

Figura 3: Deposição irregular de RCD.

Fonte: os autores.

\section{METODO DE PESQUISA}

Essa pesquisa exploratória foi realizada com dados secundários por meio das informações publicadas em Morais (2006), Shneideir (2003) e Carneiro (2005), que realizaram importantes estudos sobre a deposição inadequada de RCD nos municípios de Uberlândia/MG, São Paulo/SP e Recife/PE.

Os dados apresentados nestes trabalhos foram compilados de forma a tornar possível estabelecer situações comuns entre os três municípios estudados. O quadro seguinte apresenta um resumo das dissertações utilizadas para esta pesquisa. 


\begin{tabular}{|c|c|c|}
\hline Autor & Título & Resumo \\
\hline $\begin{array}{l}\text { Shneideir (2003) } \\
\text { Mestrado em Saúde } \\
\text { Pública } \\
\text { Universidade de São } \\
\text { Paulo }\end{array}$ & $\begin{array}{c}\text { "Deposições irregulares } \\
\text { de resíduos da construção } \\
\text { civil na cidade de São } \\
\text { Paulo" }\end{array}$ & $\begin{array}{l}\text { Este trabalho investigou possíveis causas da } \\
\text { persistência da deposição irregular de RCD em vias e } \\
\text { logradouros públicos da cidade de São Paulo, de } \\
\text { forma a gerar subsídios para a implementação de } \\
\text { políticas públicas relacionadas à limpeza urbana } \\
\text { municipal, com a finalidade de contribuir para a } \\
\text { melhoria da saúde e qualidade de vida no município } \\
\text { de São Paulo. }\end{array}$ \\
\hline $\begin{array}{c}\text { Morais (2006) } \\
\text { Mestrado em } \\
\text { Engenharia Civil } \\
\text { Universidade Federal } \\
\text { de Uberlândia/MG }\end{array}$ & $\begin{array}{l}\text { "Diagnóstico da } \\
\text { deposição clandestina de } \\
\text { resíduos de construção e } \\
\text { demolição em bairros } \\
\text { periféricos de } \\
\text { Uberlândia: subsídios } \\
\text { para uma gestão } \\
\text { sustentável" }\end{array}$ & $\begin{array}{l}\text { Esta pesquisa consistiu em um estudo de caso, que } \\
\text { possibilitou a realização de um diagnóstico da } \\
\text { situação das deposições irregulares de RCD na } \\
\text { periferia da cidade de Uberlândia. Esta pesquisa } \\
\text { propôs, ao final, sugestões de ações para } \\
\text { implementação de um plano de gestão sustentável } \\
\text { desses resíduos. }\end{array}$ \\
\hline $\begin{array}{c}\text { Carneiro (2005) } \\
\text { Mestrado em } \\
\text { Engenharia Urbana } \\
\text { Universidade Federal } \\
\text { da Paraíba }\end{array}$ & $\begin{array}{l}\text { "Diagnóstico e ações da } \\
\text { atual situação dos } \\
\text { resíduos de construção e } \\
\text { demolição na cidade do } \\
\text { Recife" }\end{array}$ & $\begin{array}{l}\text { O estudo elaborou uma análise preliminar da situação } \\
\text { ambiental dos Resíduos de Construção e Demolição } \\
\text { na Cidade do Recife. A metodologia consistiu na } \\
\text { revisão da literatura e legislação, caracterização dos } \\
\text { resíduos, mapeamento dos pontos de deposição legais } \\
\text { e ilegais, identificação de impactos ambientais } \\
\text { gerados pelos RCDs, estimativa da geração de RCD, } \\
\text { identificação de ações de adequação à Resolução } \\
\text { CONAMA n } \text { n }^{\circ} 307 \text { e a realização de um estudo } \\
\text { visando comprovar a viabilidade técnica de uma } \\
\text { alternativa de utilização do RCD reciclado. }\end{array}$ \\
\hline
\end{tabular}

Figura 4: Resumo das dissertações utilizadas nesta pesquisa.

Fonte: os autores.

\section{ANÁLISE E DISCUSSÃO DOS RESULTADOS}

Os dados secundários, obtidos de cada município, foram sintetizados para a análise e comparação dos principais aspectos relacionados aos RCDs.

\subsection{Aspectos gerais da situação do município de São Paulo}

Na cidade de São Paulo, os RCDs gerados atingem proporções da massa de RSU na ordem de 41 a $70 \%$. Schneider (2003) cita que, segundo estimativas da Secretaria Municipal de Planejamento, em 2001 viviam no município de São Paulo 10,5 milhões de habitantes. Adotando-se uma geração de RCD per capita de 0,5 toneladas/habitante/ano, estima-se que foram gerados naquele ano, no município, aproximadamente, 5,2 milhões de toneladas, ou seja, 16000 toneladas/dia.

Na cidade de São Paulo, a lei proíbe a deposição de entulhos em vias e logradouros públicos e permite que o imóvel gerador encaminhe um máximo de $50 \mathrm{~kg}$ de entulho/dia para ser recolhido pela Prefeitura por meio da coleta domiciliar, desde que os resíduos estejam devidamente acondicionados. Outra opção consiste no encaminhamento destes resíduos para Ecopontos, ou seja, unidades destinadas ao descarte gratuito diário de até $1 \mathrm{~m}^{3}$. Na medida em que são geradas quantidades superiores à estabelecida em lei, o gerador será o responsável pela remoção e destinação do RCD. Dessa forma, se faz necessária a contratação de serviço de transporte e 
remoção a serem executados por empresas cadastradas junto à Limpurb. A tabela seguinte apresenta a quantidade de Ecopontos instalados no município de São Paulo.

Tabela 6: Quantidade de Ecopontos disponíveis por região.

\begin{tabular}{|l|c|}
\hline \multicolumn{1}{|c|}{ Região } & Quantidade \\
\hline Zona Sul & 11 \\
\hline Zona Leste & 22 \\
\hline Zona Norte & 12 \\
\hline Zona Oeste & 03 \\
\hline Centro & 07 \\
\hline \multicolumn{2}{|c|}{ Total: 55 } \\
Fonte: PMSP (2012).
\end{tabular}

Deve-se ressaltar que, mesmo ilegal, uma parte da destinação final de todo este volume de RCD gerado é realizada de modo inadequado, quer seja pelo lançamento destes em terrenos baldios ou mesmo em logradouros públicos.

Schneider (2003) comenta que entre 1993 e 2002 os aterros Itatinga e Itaquera receberam da coleta pública corretiva cerca de 8.238.019 toneladas de RCD removidos de vias e logradouros municipais, o que corresponderia a um custo de $\mathrm{R} \$ 263.616 .608,00$ aos cofres públicos. Ao se considerar a população média na época, pode-se estimar um custo de, aproximadamente, R $\$$ 25,00/habitante durante este período.

O transporte privado de RCD consiste em uma atividade regulamentada na cidade de São Paulo, sendo obrigatório o cadastramento destas empresas junto a Limpurb (empresa municipal responsável pela limpeza urbana). Entretanto, apesar da Limpurb manter em seu website uma lista de empresas regulares aptas a lidar com a remoção de transporte de RCD, existe a ocorrência de atividades de empresas irregulares, mantidas por geradores de RCD indiferentes, desinformados ou somente interessados nos baixos preços das caçambas. Segundo Schneider (2003), estas empresas irregulares acabam atraindo para a ilegalidade empresas inicialmente regularizadas, ou mesmo, em caso ultimo, proporcionando sua quebra.

Segundo o mesmo autor, o lançamento de RCD em logradouros e vias públicas tende a variar em relação ao Índice de Desenvolvimento Humano (IDH) das regiões da cidade. O autor percebeu que locais caracterizados por índices mais baixos apresentam maiores volumes de entulho lançado em locais inadequados. Dito de outra maneira, regiões com IDH baixo e muito baixo alugam menor número de caçambas de transportadores formais, portanto, estão mais sujeitas à deposição irregular de RCD em vias e logradouros públicos.

\subsection{Aspectos gerais da situação do município de Uberlândia/MG}

No município de Uberlândia/MG, aproximadamente, 95\% do sistema de coleta de Resíduos Sólidos Urbanos (RSUs) é terceirizado. Estima-se que o volume de RCD consiste em cerca de 64\% do total de RSU gerado por dia. Dados provenientes de pesquisa encomendada pela prefeitura, em 2000, indicam que a quantidade de resíduos removidos pela Adminstração Pública situou-se em média de 240,5 toneladas/dia. A somatória de todos os dados levantados, incluindo-se também RCD gerado por obras de construção e reformas de edifícios, indicaram uma quantidade de 958 toneladas/dia, ou seja, tal número representa quase $2 \mathrm{~kg} /$ habitante/dia. Parte considerável deste resíduo é descartada em regiões inadequadas, sendo identificados no ano de 2000 mais de 150 pontos de deposição irregular. De uma forma geral, os agentes responsáveis por estas deposições são compostos por empresas de transporte e coleta irregulares, carroceiros e proprietários de pequenas obras. Observa-se também que, quão mais carente se apresenta a região do município, maior a incidência de pontos de descarte de RCD inadequados (terrenos baldios, logradouros e vias públicas). Tal situação pode ser explicada, uma vez que tais regiões, além de serem menos 
urbanizadas, apresentando assim maior área disponível para descarte, também são compostas por população de baixa renda, que não contrata serviços de coleta e transporte adequados, segundo Morais (2006).

O município conta atualmente com cinco Ecopontos, e dezoito centrais de entulho distribuídos em diversas regiões. Uberlândia também conta com Sistema Municipal para Gestão Sustentável de Resíduos da Construção Civil e Resíduos Volumosos, voltado à facilitação da correta disposição, disciplinamento do fluxo e agentes envolvidos e à destinação adequada dos RCDs e volumosos produzidos em Uberlândia. Este sistema foi instituído pela Lei Municipal $\mathrm{n}^{\circ}$ 9.244 de 26 de junho de 2006. Entre um conjunto de ações, esta lei prevê em específico para a deposição de RCD, a implantação de uma rede de centrais para a coleta de pequenos volumes (até $2 \mathrm{~m}^{3}$ ); sistema de disque-coleta; redes de áreas de recepção de grandes volumes, constituídas por áreas de transbordo e triagem (ATTR) e ações para controle e fiscalização dos agentes envolvidos.

\subsection{Aspectos da situação do município de Recife/PE}

$\mathrm{Na}$ cidade de Recife, segundo Carneiro (2005), o volume diário de RCD recolhido pelas empresas locais corresponde a cerca de $840 \mathrm{~m}^{3} / \mathrm{dia}$, o que equivale a, aproximadamente, 1142,4 toneladas por dia. No prazo de um ano, segundo os dados informados, o município de Recife teria acumulado em 2005 cerca de 356.428,80 toneladas de RCD. Na tabela seguinte, é apresentada a composição, em porcentagem, do RCD gerado em Recife.

Tabela 7: Composição do RCD do município de Recife.

\begin{tabular}{|l|c|}
\hline \multicolumn{1}{|c|}{ Origem do RCD } & Composição (\%) \\
\hline Reformas e ampliações térreas & 17 \\
\hline Construção de edifícios multipiso & 57 \\
\hline Coleta industrial serviços & 7 \\
\hline Construção de residências térreas & 10 \\
\hline Limpeza de terrenos & 6 \\
\hline Demolições & 6 \\
\hline
\end{tabular}

Fonte: Carneiro (2005).

Ressalta-se que estes parâmetros referem-se às medições efetuadas, utilizando-se informações de empresas devidamente legalizadas, ou seja, se for considerada, nesta conta, a quantidade de material depositado em locais inadequados (vias, logradouros e terrenos baldios) esse número tenderá a aumentar significativamente.

A Emlurb, empresa municipal responsável pela limpeza urbana, opera a coleta dos resíduos sólidos provenientes da construção civil, desde que devidamente acondicionados, em volume até de $0,30 \mathrm{~m}^{3}$, por meio da coleta regular de lixo. Com a implantação do Decreto $\mathrm{n}^{\mathbf{0}} 18.082 / 98$, que regulamenta a Lei Municipal $\mathrm{n}^{\circ}$ 16.377/98, a execução dos serviços de limpeza pública, recolhimento, transporte e disposição dos resíduos, foi definido que a remoção de volumes acima dos $0,30 \mathrm{~m}^{3}$, deverá ser realizada por terceiros, por meio da contratação de firmas especializadas, mediante prévio cadastramento na Emlurb.

O único aterro devidamente legalizado e adequado para a destinação dos RCDs gerados no município, o Muribeca, está localizado na Estrada da Integração dos Prazeres, em Jaboatão dos Guararapes. Este aterro possui área de 62 hectares e tem capacidade para receber, em média, 3000 toneladas/dia de RSU provenientes dos municípios de Jaboatão dos Guararapes e Recife, que compartilham sua operação com o governo do Estado de Pernambuco.

Segundo Carneiro (2005), baseado em dados fornecidos pela Emlurb, no ano de 2004, foram depositadas, aproximadamente, 2822 toneladas/ano de RCD no aterro Muribeca. Contudo, esta quantidade representa somente $10,7 \%$ do total de RSU encaminhado para o aterro. Esse pequeno 
percentual é de fato alarmante. $\mathrm{O}$ fato de que apenas uma pequena parcela de RCD (em relação ao total de RSU) é depositada em uma área legalizada, indica que a grande maioria dos resíduos de construção e demolição está sendo lançada em áreas inapropriadas.

De fato, Carneiro (2005) comenta que cerca de 353.606 toneladas de RCD foram depositadas clandestinamente na cidade do Recife em 2004. Ao considerar as atuais condições favoráveis da construção civil, este número, hoje em dia, poderá já ter assumido magnitudes alarmantes.

Estima-se que o município do Recife possua mais de 180 pontos de lançamento inadequado de RCD, sendo estes predominantemente localizados em áreas pouco desenvolvidas, próximo dos cursos d'água, regiões de preservação ambiental e manguezais.

\section{CONSIDERAÇÕES FINAIS}

O objetivo desta pesquisa é analisar o problema de geração e destinação final de resíduos sólidos de construção civil e seus impactos na saúde coletiva por meio de um estudo comparativo em três municípios brasileiros: São Paulo/SP, Uberlândia/MG e Recife/PE. A pesquisa exploratória, realizada por meio de dados secundários, atingiu o objetivo proposto ao mostrar a problemática da deposição irregular de resíduos de construção e demolição e seu impacto na saúde coletiva.

O resultado do estudo mostrou que os resíduos de construção e demolição constituem grande parte do volume de resíduos sólidos urbanos gerados diariamente, atingindo valores de até $70 \%$. Nos três municípios, as regiões onde ocorreram as maiores quantidades de deposições irregulares de RCD são aquelas que apresentam baixos índices de desenvolvimento social situadas em zonas de periferia.

Observa-se também que a maior parte do volume de RCD despejado em áreas irregulares (logradouros, terrenos baldios, vias públicas, etc) provém de pequenas construções residenciais e reformas, sendo o transporte operado por empresas irregulares ou carroceiros.

As empresas municipais, das cidades estudadas, operam sistemas de coleta de resíduos sólidos provenientes da construção civil, desde que devidamente acondicionados e em volumes máximos de acordo com cada legislação.

Há a necessidade de adoção, por parte do poder público, de medidas que coíbam o transporte e a deposição de RCD em áreas inapropriadas. Apesar de consistir em atividade ilegal, agentes irregulares transportam e despejam diariamente grandes volumes deste tipo de resíduo em regiões baldias e públicas. É necessária também a conscientização dos geradores de RCD e a implantação de mais áreas apropriadas e devidamente regulamentadas para a destinação de RCD.

A gestão inadequada de RCD oferece riscos a saúde coletiva, variado de proliferação de vetores, exposição não controlada de resíduos potencialmente perigosos, entupimento dos sistemas de drenagem urbana e degradação da paisagem urbana.

A principal limitação dessa pesquisa é o fato de trabalhar com dados secundários que foram obtidos para o propósito dos estudos analisados, o que, de certa forma, dificultou o aprofundamento dos casos.

Para futuros estudos, recomenda-se a análise da destinação de RCD com dados do IBGE, buscando identificar a situação dos municípios brasileiros relacionando com dados de saúde pública. 


\section{REFERÊNCIAS}

Araujo, J. M.(2000) Caçambas coletoras de resíduos sólidos e riscos à saúde pública: um enfoque segundo os princípios da atenção primária ambiental. São Paulo. 138f. Dissertação (Mestrado em Saúde Pública) - Faculdade de Saúde Pública, Universidade de São Paulo.

Associação Brasileira de Normas Técnicas-ABNT.(2004) NBR10004: "Resíduos sólidos classificação”, Rio de Janeiro, 71p.

Carneiro, F.P. (2005) Diagnóstico e ações da situação atual dos resíduos de construção e demolição na cidade do Recife. 2005. 132p Dissertação (mestrado). Universidade Federal da Paraíba. João Pessoa/PB.

Conselho Nacional do Meio Ambiente -Conama(2002): Resolução n ${ }^{\circ} .307$, de 05 de julho de 2002. Estabelece diretrizes, critérios e procedimentos para a gestão dos resíduos da construção civil. Diário Oficial da União, Brasília, DF, Recuperado em: 17 de julho de 2002, de: <http://www.mma.gov.br/port/conama/-index.cfm>.

Caixa Econômica Federal - CEF(2005). Manejo e gestão de resíduos da construção civil. Brasília: CAIXA, 194 p. Dezembro de 2005 de: 〈http://ww.caixa.gov.br〉.

Dias, J. F. (2004) A construção civil e o meio ambiente. In: Congresso Estadual de Profissionais CREA - MG. Anais. Uberlândia: CREA.

Fernandes, M.P.M. et al.(2010) A modificação da paisagem urbana e os resíduos da construção e demolição. In: Simpósio Iberoamericano de Ingenieria de Residuos, 3; Seminário da Região Nordeste sobre resíduos sólidos, 2, João Pessoa, $\mathrm{Pb}$, Brasil.

John, V.M., Agopyan, V. (2000) Reciclagem de resíduos da construção civil. In: Seminário Reciclagem de resíduos sólidos domiciliares. Secretaria de Estado do Meio Ambiente. São Paulo. $13 \mathrm{p}$.

John, V. M. (2000) Reciclagem de resíduos na construção civil: Contribuição para metodologia de pesquisa e desenvolvimento. São Paulo. 113p. Tese (Livre Docência) - Escola Politécnica da Universidade de São Paulo. Departamento de Engenharia de Construção Civil.

Morais, G.M.D. (2006) Diagnóstico da deposição clandestina de resíduos de construção e demolição em bairros periféricos de Uberlândia: Subsídios para uma gestão sustentável. 2006. 220p Dissertação (mestrado). Faculdade de Engenharia Civil. Universidade Federal de Uberlândia. Uberlândia/MG., 2009.

Pinto, T. P. (1999) Metodologia para a gestão diferenciada de resíduos sólidos da construção urbana. 1999. Tese (Doutorado) - Universidade de São Paulo, Escola Politécnica da Universidade de São Paulo, São Paulo.

Prefeitura Municipal de São Paulo - PMSP (2012). Ecoponto: Estação de entrega voluntária de inservíveis. Recuperado em Julho de 2012, de: 〈http://ww.prefeitura.sp.gov.br >. 
Schneider, D.M.(2003) Deposições irregulares de resíduos da construção civil na cidade de São Paulo. 2003. 131p Dissertação (mestrado). Universidade de São Paulo, Escola Politécnica da Universidade de São Paulo, São Paulo.

Takata, T. (2003) Survey on the health effects of chronic exposure to dioxins ant its accumulation on workers of a municipal waste incinerator, rural parto $f$ Osaka Prefecture, and the result of extended survey afterwards. Industrial Health, 41(3),189-196.

Data do recebimento do artigo: 21/06/2011

Data do aceite de publicação: 13/02/2012 